\title{
Legibilidade para a Terceira Idade
}

\section{Legibility for the Elderly}

FARIAS, Bruno Serviliano Santos; Doutorando; UNESP - Bauru

brunoserviliano@ufma.br

LANDIM, Paula da Cruz; Doutora; UNESP - Bauru

paula@faac.unesp.br

\section{Resumo}

O presente artigo tem como objetivo discutir o efeito do processo de envelhecimento na atividade de leitura com o intuito de analisar quais variáveis tipográficas são mais eficientes. Para tal, esse estudo propõe um método comparativo de fontes para avaliar o Efeito Aglomerativo. Tal efeito se relaciona com a diminuição do contraste visual proveniente da relação entre branco e preto da linha do texto. Os resultados apontam que o espaço entre letras, o peso do traço e os espaços internos são importantes para uma legibilidade inclusiva para a Terceira Idade.

Palavras Chave: legibilidade; terceira idade; efeito aglomerativo.

\begin{abstract}
The present article aims to discuss the effect of the aging process on the reading activity in order to analyze which typographic variables are more efficient. For this, this study proposes a comparative method of sources to evaluate the Crowding Effect. This effect is related to the decrease of the visual contrast which comes from the ratio between white and black of the text line. The results indicate that the space between letters, the weight of the trace and the internal spaces are important for an inclusive readability for the Third Age.
\end{abstract}

Keywords: legibility; elderly; crowding effect. 


\section{Introdução}

O envelhecimento populacional tem sido um desafio para todos os países, incluindo o Brasil. Em 1940, 4\% da população brasileira era considerada idosa, representando 1,7 milhões de pessoas. Em 2020 serão 30,9 milhões (CAMARANO, KANSO e MELLO, 2004). A expectativa de vida saltou de 66 anos em 1990 para 73 anos em 2007 (FERRIGNO, 2010). Devido a esse fato, o prolongamento da vida tem promovido mudanças no perfil social e tem conduzido debates, repensando o bem-estar, debilidades e autonomia.

A velhice pode ser compreendida como um processo complexo marcado por mudanças relacionadas às capacidades funcionais (motora, sensorial e cognitiva) (CAMARANO E PASINATO, 2004). Em 2000, 30\% dos idosos brasileiros declararam possuir algum tipo de problema visual (CAMARANO, KANSO e MELLO, 2004). O declínio da acuidade visual tem início aos 40 anos e provoca a diminuição da percepção visual e a dificuldade em se adaptar ao brilho. A lente ocular, no processo de envelhecimento, se torna opaca e menos elástica, representando menos luz, dificultando a percepção de objetos próximos (CLARKSON ET AL, 2013). A perda do campo central e periférico da visão é um dos problemas enfrentados na Terceira Idade em especial para quem sofre com diabetes, afirma Nine (2006).

Segundo Meürer, Gonçalves e Correio (2014) e Vieira (2011), há quatro tipos diferentes de problemas de visão que provocam baixa acuidade visual, que são: Degeneração muscular, Glaucoma, Retinopatia diabética e Catarata. Tais problemas visuais podem ser representados na figura 1.

Figura 1 - Simulação dos problemas de visão

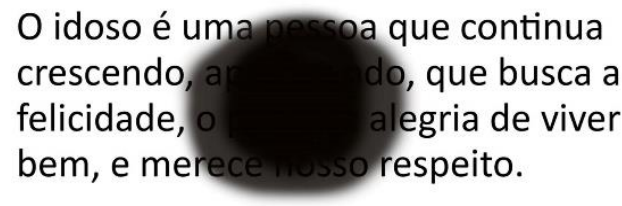

visão com degeneração macular

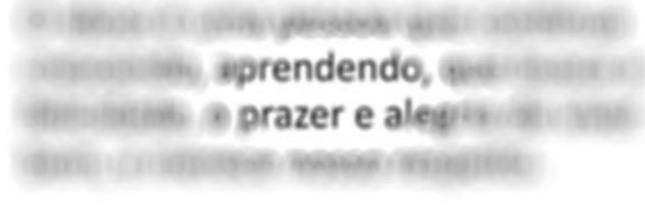

Visão com glaucoma

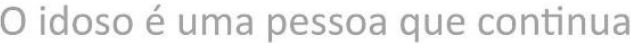
crescendo, aprendendo, que busca a felicidade, o prazer e alegria de viver bem, e merece nosso respeito.

Diante disso, Vieira (2011) comenta que é comum muitos idosos se sentirem analfabetos em decorrência de problemas de visão. Desconsiderar esses problemas torna o processo de design gráfico excludente. Por essa razão, deve-se valorizar o planejamento de artefatos gráficos como materiais didáticos das Universidades da Terceira Idade, bulas de remédio, jornais e revistas, telas digitais, entre outros suportes gráficos com o intuito de diminuir o grau de exclusão e proporcionar melhor qualidade de vida a uma parcela cada vez mais significativa da população.

Assim, o objetivo desse artigo é discutir os elementos tipográficos que impactam 
significativamente a legibilidade, como o tamanho das fontes, o contraste textual e aspectos da anatomia tipográfica, considerando o processo de envelhecimento e o declínio da acuidade visual.

\section{Anatomia tipográfica para leitura}

A legibilidade é a seleção adequada de letras considerando seus aspectos formais e característica do público. Os aspectos formais se relacionam com a anatomia do tipo. A característica do público se relaciona com dificuldades de percepção. Dessa forma para se conhecer uma letra é necessário abstrair todos os tipos de características das fontes que potencializam os ruídos visuais nos leitores, comenta Leeuw (2010).

O uso progressivo da escrita em larga escala propiciou uma expressão tipográfica concisa que permitiu a valorização da legibilidade, comenta Frutiger (2007). O autor explica que a forma da letra que fosse modificada radicalmente perderia a qualidade, encontraria resistência e prejudicaria a leitura.

Dialogando com essas ideias, Tschichold (2010) considera que a tipografia perfeita é mais ciência do que arte. $\mathrm{O}$ autor argumenta que a escolha dos tipos diz respeito a todos, uma vez que seria inútil se não fosse universal. Tschichold (2010) ainda afirma que cinquenta anos de experimentações produziu a percepção de que as fontes clássicas são as melhores, mas na verdade é a similaridade de todas as letras e a nitidez de cada caractere que gera a perfeita legibilidade, comenta o autor.

Fontes clássicas, reconhecimento fácil e elementos de diferenciação são premissas que se tornam ainda mais significativas quando se considera as deficiências individuais para se projetar um artefato gráfico inclusivo. Desconsiderar como o processo de envelhecimento ocorre é permitir ruídos nos estímulos visuais que prejudicam a performance da leitura.

Ruídos visuais são problemas na percepção relacionados à leitura. Leeuw (2010) afirma que as fontes podem melhorar o limiar perceptivo, reduzindo os ruídos de quem tem problemas de visão. Contudo, Sousa (2002) explica que não é a qualidade do design de letras que precisa ser melhorado e sim como ele é utilizado. Em um primeiro momento uma fonte pode ser adequada para a maioria das situações, no entanto, com algumas alterações é possível melhorar a rapidez de leitura e a compreensão da mensagem.

À vista disso, será realizada uma discussão sobre as articulações tipográficas, com suas variáveis que possuam impacto na leitura na Terceira Idade. O propósito será desenvolver um método que possa discutir quais fontes poderiam ter um desempenho melhor de leitura.

\subsection{Tamanho}

O tamanho da letra talvez seja a principal articulação tipográfica para melhorar a legibilidade. Letras muito pequenas dificultam a leitura, principalmente de pessoas com limiar perceptivo visual comprometido. Kitchel (2018) explica que o tamanho mínimo para pessoas com baixa visão é 12 pontos para documentos. Impressões ampliadas se devem utilizar de 14 a 16 pontos. Pessoas que precisam de letras maiores que 28 pontos devem ser considerados candidatas à educação em braile.

Ao pesquisar com 27 idosos, entre 62 e 83 anos, Bernard, Liao e Mills (2001), fizeram testes com fontes com tamanhos de 12 e 14 pontos. Eles concluíram que as fontes que possuem 14 . 
Pontos de tamanho apresentaram leitura mais rápida ou propiciaram uma leitura mais rápida, com menos erros, sendo as preferidas pelos idosos. Algo semelhante foi encontrado com Leeuw (2010) sobre a preferência do tamanho das fontes e da velocidade. Assim, se poderia afirmar que o tamanho das fontes ideal para leitura de idosos seria entre 12 a 16 pts. Com esses tamanhos se poderia atingir o menor tempo de leitura e com menores incidências de erros (figura 2).

Figura 2 - Tamanho de fonte ótimo para a Terceira Idade

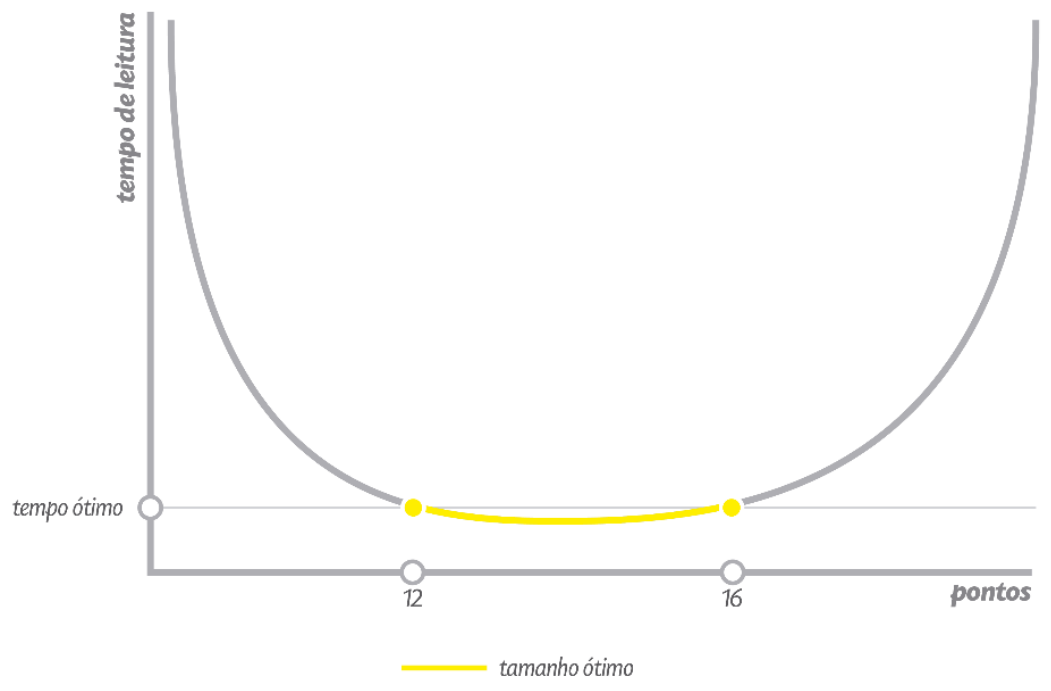

Fonte: dos autores

De qualquer forma, a legibilidade não é só uma questão de tamanho. Letras grandes são mais legíveis quando lidas isoladamente, no entanto, não favorecem uma leitura ou compreensão rápida Burt, Cooper e Martin (1955). Tornar o texto visível é diferente de torná-lo fácil de ler (GROEGER, 2016). Por isso é necessário compreender o impacto das outras variáveis tipográficas.

\subsection{Contraste do traço}

Araújo (2012) esclarece que a haste é o traço principal que define a letra. Pode ser reto, obliquo ou curvo. Além da forma, ele também pode variar com relação ao contraste. Sousa (2002) e Bringhurst (2007) comentam que o contraste, ou modulação, é formado pela diferença da espessura entre as hastes podendo ser grande, médio ou nulo, como na figura 3. Em fontes Românticas, como Bodoni, o contraste é grande. Sem contraste, sem modulação, comenta o autor. 
Figura 3 - Contraste do traço

CONTRASTE

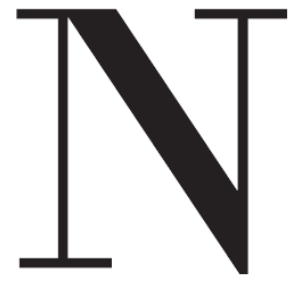

grande
Bodoni MT

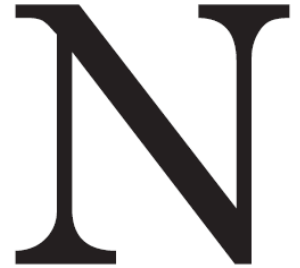

médio

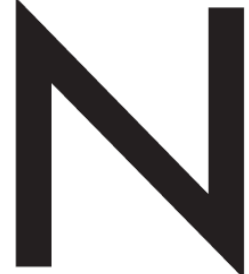

nulo
Tw Cen

Fonte: Sousa (2002)

Para pessoas com baixa visão os traços finos são inadequados por quebrarem as letras. Por outro lado, traços com contraste nulo melhoram a legibilidade (NINE, 2006). Nesse sentido, as grandes modulações tendem a gerar ruídos de informação durante a leitura. Letras sem modulação tende a gerar menos ruídos.

O contraste entre branco e preto é fundamental para o processo de leitura dos idosos. Os espaços em preto são definidos pelas hastes (círculos coloridos na figura 4). A espessura do traço também define o peso da letra. O peso é, de acordo com Bringhurst (2007), o grau de escuridão. Ele pode melhorar a legibilidade do texto em especial para pessoas com baixa visão devido à maior superfície de impressão. Quanto maior for essa superfície mais pesada e mais visível será a letra. Essa relação, peso e visibilidade são diretamente proporcionais e favorecem o limiar perceptivo. Os espaços em branco estão relacionados pelo entre letras, olhos e aberturas (círculo pontilhado na figura 4).

Figura 4 - Contraste entre branco e preto

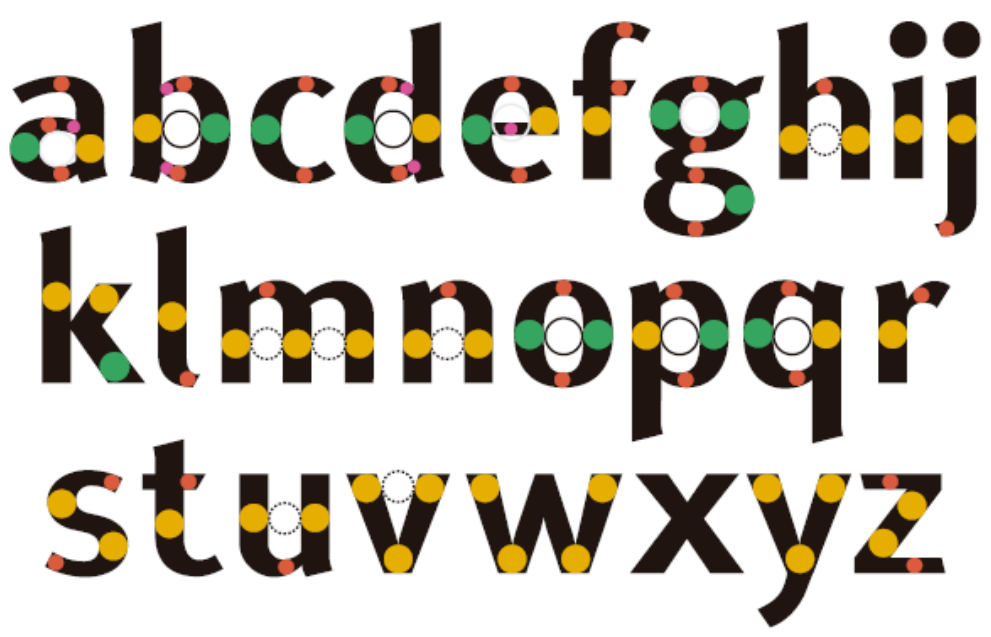

Fonte: Unostiposduros (2010) 


\subsection{Extensão das hastes}

As hastes podem se prologar para cima ou para baixo. Sousa (2002) e Bringhurst (2007) definem a ascendente como parte da letra minúscula que se ergue acima da linha mediana ("b", "d", " $h$ ", "k", "l" e " $t$ " - parte em verde da figura 5) e descendente é a parte da letra minúscula que passa abaixo da linha de base (" $p$ " e " $q$ " - parte em verde na figura 5).

As letras não podem ter ascendentes e descendentes curtas devido à dificuldade em perceber e diferenciar letras como " $n$ " e " $h$ " ou o "o" e "p", explica Sousa (2002). O prolongamento permite melhorar a diferenciação de algumas letras. A estratégia de diferenciação é fundamental para o desempenho da leitura que interfere na velocidade e na compreensão. Ademais, o prolongamento das hastes melhora a legibilidade por aumentar a entrelinha, suscitando uma quantidade automática de branco (ARAÚJO, 2012).

Figura 5 - Hastes, ascendentes e descendentes

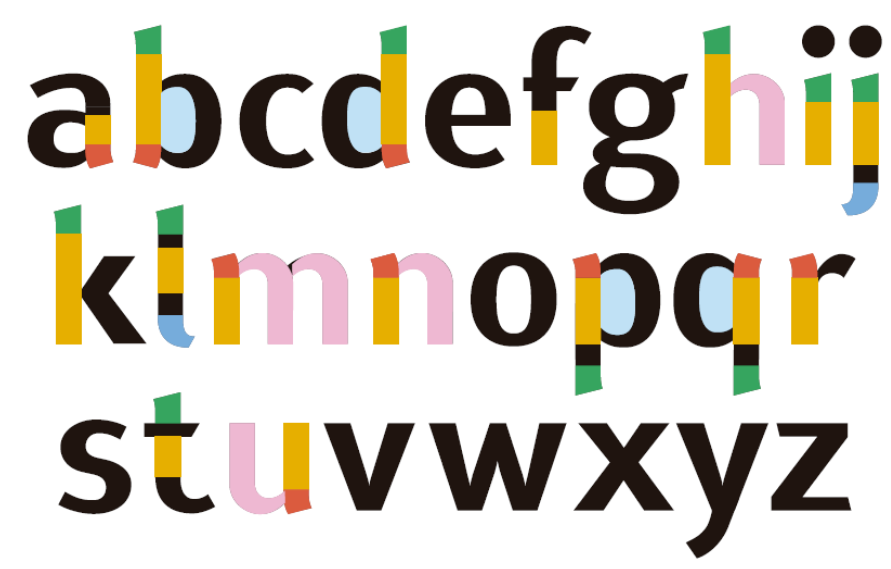

Fonte: Unostiposduros (2010)

\subsection{Altura-x, olho e abertura}

A altura-x define a mediana e o tamanho das minúsculas, explica Sousa (2002). A velocidade de leitura é influenciada pela altura-x. Quanto maior for a altura-x mais rápido se lê, comenta Leeuw (2010).

Bringhurst (2007) afirma que "a legibilidade das letras não depende apenas de suas formas ou da tinta que as imprime, mas também do espaço vazio esculpido entre elas e à sua volta". 0 espaço em branco em uma página torna o texto mais legível por favorecer o contraste, incluindo entrelinhas e margem, comenta Kitchel (2018).

O olho e a abertura também têm impactos na superfície impressa das letras. O primeiro é delimitado pelo espaço em branco que o contorno interno estabelece, explica Sousa (2002). Bringhurst (2007) cita as letras "c", "s", "a" e "e" para apontar letras com aberturas. O autor ainda comenta que o estilo Humanista, como a fonte Bembo, tem aberturas maiores e os estilos Romântico e Realista, como a fonte Bodoni e a Helvética, tem aberturas menores. O contraste de letra ideal seria aquele que valorizasse tanto a espessura do traço quanto os espaços internos (figura 6). 
Figura 6 - Contraste entre traço e espaço interno

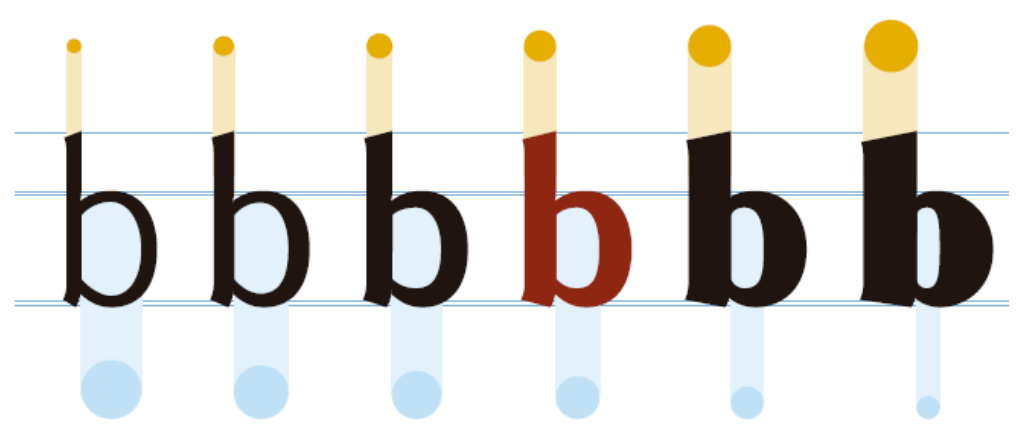

Fonte: Unostiposduros (2010)

O contraste exerce um peso maior para pessoas com problemas de visão. Obviamente, cada problema tem um impacto singular na percepção comprometendo o foco, o contraste, o campo de visão. Dificilmente será a tipografia que resolverá o problema de visão. Contudo, reconhecer os limiares perceptivos e os limites de atuação da tipografia pode melhorar a qualidade de vida de pessoas com deficiências visuais.

As pesquisas científicas, citadas ao longo desse artigo, convergem para alguns princípios gerais como tamanho de letra, estilo de traço e valorização dos espaços em branco para gerar contraste. Todos esses princípios se relacionam com o efeito aglomerativo.

\subsection{Efeito Aglomerativo}

Efeito Aglomerativo refere-se ao agrupamento das letras, dificultando a distinção destas (figura 7). Ele se relaciona diretamente com o espaço entre as letras. Quanto maior for a aglomeração das letras menor será o contraste com o fundo (PIJPKER, 2013). Dessa forma, o Efeito Aglomerativo reduz a velocidade de leitura (CHUNG, 2002). A variável que se modifica para ocorrer tal efeito é o deslocamento horizontal do entre letras. Quanto mais próximas forem as letras, ou menos espaço em branco houver, menos distinguíveis elas serão, formando só uma mancha preta.

Figura 7 - Efeito Aglomerativo

Texto composto de uma forma apertada (tighthy), será difíil de ler. As letras levam muito tempo a serem distinguidas pois o espaçamento entre elas é inadequado.

Fonte: Sousa (2002)

Não por acaso que fontes com serifas tendem a apresentar bons desempenhos de leitura, principalmente no critério de velocidade de leitura. A principal razão, para Arditi e Cho (2005), não é o aumento dos elementos de diferenciação, nem a capacidade de facilitar o movimento do olho, até porque para os autores a leitura é realizada em blocos de palavras e a serifa é um elemento muito pequeno da área de impressão das letras, podem inclusive gerar ruído visual para pessoas 
com baixa visão. A principal razão, de acordo com os autores, é o espaçamento entre letras que é maior em fontes com serifas para poder acomodá-las.

Diante dessas questões o presente estudo se propõe a desenvolver um parâmetro de análise de legibilidade tipográfica.

\section{Pesquisa Sobre Efeito Aglomerativo}

A proposta de análise do Efeito Aglomerativo ocorrerá em três etapas. A primeira está relacionada à seleção de fontes, a segunda é a mensuração das variáveis e a terceira é a análise do Efeito Aglomerativo.

A seleção das fontes teve como critério a recorrência das fontes mais empregadas em pesquisas sobre legibilidade com idosos ou pessoas com problemas de visão (BURT, COPPER E MARTIN, 1955; CHUNG, 2002; PIJPKER, 2013; KITCHEL, 2018; LEEUW, 2010; NINIE, 2006; BERNARD, LIAO e MILLS; 2001 e FARIAS, GUIMARÃES e MARQUES; 2017). As quatro fontes com maiores recorrências foram: Arial, Verdana, Times New Roman e Georgia.

\subsection{Altura-x, olho e ascendentes e descendentes}

Para análise foram consideradas as supracitadas fontes com 16 pts., formando uma linha de 26 letras dispostas em sequência, desta serão mensuradas:

- O comprimento da linha;

- A espessura da haste;

- Os espaços internos dos olhos e das aberturas;

- A dimensão da altura-x;

- Extensões e

- Entre letras.

Os dados da mensuração estão no quadro 1.

Quadro 1 - Tabulação dos dados descritivos das fontes

\begin{tabular}{lcccc}
\hline Medias em milímetro & Arial & Verdana & Times New Roman & Georgia \\
\hline Comprimento da linha (l) & 71 & 82 & 67 & 73 \\
\hline Espessura da haste (h) & 0,4 & 0,5 & 0,4 & 0,5 \\
\hline Altura-x & $\mathbf{2 , 9}$ & $\mathbf{3 , 0}$ & $\mathbf{2 , 5}$ & $\mathbf{2 , 7}$ \\
\hline Espaço interno do "n" & 1,4 & 1,5 & 1,0 & 1,1 \\
\hline Espaço interno do "c" & 1,5 & 1,9 & 1,6 & 1,6 \\
\hline Espaço interno do "b" & 1,5 & 1,6 & 1,2 & 1,3 \\
\hline Espaço interno do "o" & 1,7 & 1,7 & 1,4 & 1,5 \\
\hline Espaço interno médio (ei) & $\mathbf{1 , 5}$ & $\mathbf{1 , 7}$ & $\mathbf{1 , 3}$ \\
\hline Ascendente & 1,1 & 1,2 & 1,4 & 1,5 \\
\hline Descendente & $\mathbf{1 , 1}$ & $\mathbf{1 , 1}$ & $\mathbf{1 , 2}$ & $\mathbf{1 , 2}$ \\
\hline Extensões & $\mathbf{2 , 2}$ & $\mathbf{2 , 3}$ & $\mathbf{2 , 6}$ & $\mathbf{2 , 7}$
\end{tabular}

\footnotetext{
${ }^{1}$ Soma do ascendente com o descendente
} 


\begin{tabular}{lllll}
\hline Altura total" & 5,1 & 5,3 & 5,1 & 5,4 \\
\hline Entre letras "b/c" & 0,4 & 0,6 & 0,4 & 0,4 \\
\hline Entre letras "d/e" & 0,6 & 0,8 & 0,6 & 0,7 \\
\hline Entre letras "h/i" & 0,7 & 1,0 & 1,0 & 1,1 \\
\hline Entre letras médio (el) & $\mathbf{0 , 6}$ & $\mathbf{0 , 8}$ & $\mathbf{0 , 7}$ & $\mathbf{0 , 7}$ \\
\hline
\end{tabular}

Fonte: dos autores

Sobre os dados, a fonte Verdana apresenta maior Altura-x e maiores Espaços internos e maiores médias Entre letras. A fonte Times New Roman tem a menor Altura-x e o menor Espaços internos. A fonte Arial apresenta menores médias de Entre letras. Diante desses dados foi proposto um Método de Análise para o cálculo do Efeito Aglomerativo.

\subsection{Proposta de Cálculo Aglomerativo}

Para o cálculo do Efeito Aglomerativo será considerado o Contraste da letra e o Espaço impresso e o Espaço não impresso da linha.

- O contraste da letra: é o produto entre Espessura da haste e Espaço interno Médio. Desta forma se tem a relação do espaço impresso com espaço não impresso.

$$
c=h . e i
$$

- O Espaço não impresso da linha: é a soma entre todos os entre letras com a soma de todos os espaços internos que é dividido pelo comprimento da linha. Assim se tem um valor percentual do branco da linha.

$$
n i=\frac{(25 e l)+(26 e i)}{l}
$$

- O Espaço impresso: é a diferença entre o Comprimento da linha com o Espaço não impresso. Também é um valor percentual do preto da linha.

$$
i m=l-n i
$$

- O Efeito Aglomerativo: é a relação entre Espaço impresso pelo produto do Entre letras médio com Espaço não impresso.

$$
e a=\frac{i m}{\text { ni.el }}
$$

Assim temos os seguintes dados no quadro 2:

\footnotetext{
2 Soma da altura-x com extensões
} 
Quadro 2 - Análise do Efeito Aglomerativo

\begin{tabular}{lcccc}
\hline & Arial & Verdana & Times New Roman & Georgia \\
\hline Contraste da letra (c) & 0,6 & 0,8 & 0,5 & 0,7 \\
\hline Espaço não impresso (ni) & 0,8 & 0,8 & 0,8 & 0,7 \\
\hline Espaço impresso (im) & 0,2 & 0,2 & 0,2 & 0,3 \\
\hline Efeito Aglomerativo (ea) & $\mathbf{0 , 5 6}$ & $\mathbf{0 , 3 6}$ & $\mathbf{0 , 4 9}$ & $\mathbf{0 , 4 8}$ \\
\hline
\end{tabular}

Fonte: dos autores

Como resultado foi possível perceber a relação entre o Efeito Aglomerativo com as articulações tipográficas, gráfico 1. O Efeito Aglomerativo diminui quando se tem mais Espaço entre Letras e maior Contrastes da Letra.

Gráfico 1 - Relação Efeito Aglomerativo e Articulações tipográficas

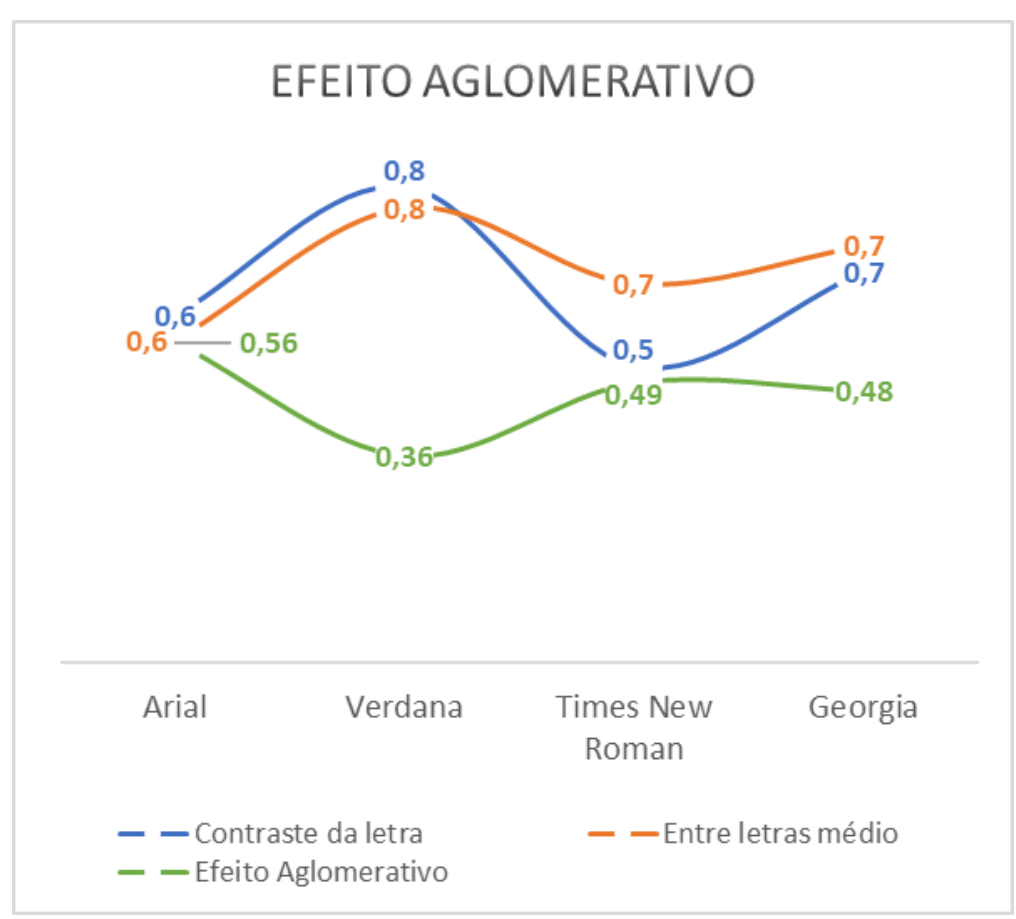

Fonte: dos autores

Comparando o resultando encontrado com outras pesquisas se tem que:

- A fonte Verdana tem o melhor Contraste da letra, possivelmente por ter maior Altura-x e menor Efeito Aglomerativo. Sousa (2002) afirma que a Verdana foi desenvolvida para resolver problemas de resolução em telas eletrônicas, por isso, comentam Meürer, Gonçalves e Correio (2014), é uma fonte com fácil percepção. A facilidade de percepção se deve à altura-x, seus espaços internos e espessura da sua haste, contribuindo para o Efeito Aglomerativo baixo. De qualquer forma, essa fonte não aumenta significativamente a velocidade de leitura ou compreensão da leitura, afirma Soares (2016). Tal fato pode ser justificado pela falta de elementos 
de diferenciação. Letras como "i", "l" e "j", são muito parecidas, além das letras "b", " $q$ ", " $d$ " e " $p$ " serem espelhadas. As extensões poderiam contribuir para os elementos de diferenciação, no entanto, essa variável não é bem explorada por essa fonte em comparação as demais.

- Times New Roman tem o pior Contraste da letra, possivelmente pela menor Altura$x$. A Times New Roman foi pensada para ser uma fonte legível para textos, com grande contraste no traço para permitir grande quantidade de palavras por linha. Essa racionalidade do espaço pode ser constatada no curto comprimento da linha, na menor altura-x e nos estreitos espaços internos que diminuem a legibilidade. Meürer, Gonçalves e Correio (2014) comentam que tal fonte apresenta algumas dificuldades de leitura em idosos, pois a Times New Roman tem serifas pequenas que geram ruídos visuais.

- A fonte Arial tem o maior Efeito Aglomerativo devido a menor Entre letras. Em vários aspectos essa fonte se assemelha com a Verdana. No entanto, a principal diferença está no espaço em branco. A Arial tem menor Espaços internos e menor Entre letra do que a Verdana, por isso tal fonte tem um elevado efeito aglomerativo. Contudo, Meürer, Gonçalves e Correio (2014) a consideram com uma excelente legibilidade quando em tamanhos maiores, como em 16 pts., porém quando em tamanhos menores pode apresentar problemas. Nesta situação é que aparece o Efeito Aglomerativo.

O presente método de investigação da legibilidade permite a comparação e verificação de fontes com o intuito de analisar as variáveis tipográficas e apontar quais teriam o melhor desempenho. As quatro fontes analisadas são consideradas de boa legibilidade, por isso são utilizadas em pesquisas do gênero. No entanto, é possível reconhecer qual teria o melhor desempenho.

O contraste é um princípio fundamental para esse público devido ao processo de envelhecimento. O espalhamento entre letras, bem como o espaço interno são articulações tipográficas que diminui tal efeito e melhoram o desempenho da leitura.

A fonte Arial apresenta boa legibilidade em tamanhos maiores como 16 pts., entretanto tamanhos menores poderiam acentuar o Efeito Aglomerativo, principalmente para idosos. A fonte Times New Roman por valorizar a racionalização do espaço pode gerar ruídos visuais. A Verdana tem um excelente Contraste de letra, com traço robusto e amplo espaço interno, no entanto possui poucos elementos de diferenciação. Por tudo isso se conclui que não há uma fonte ideal e sim fontes que valorizam certos aspectos das variáveis tipográficas, como elementos de diferenciação, hastes visíveis, entre letras generosos, entre outras citadas no artigo. A principal questão é reconhecer quais articulações tipográficas são mais significativas para o público e selecioná-las com eficiência.

\section{Considerações Finais}

Os idosos estão cada vez mais participando das atividades. Devido ao prolongamento da expectativa de vida, surge um novo perfil social, mais envelhecido, exigindo novas demandas, novas formas de exercer a qualidade de vida. O design gráfico participa desse contexto propondo 
artefatos gráficos mais inclusivos que melhoram a autonomia e o desempenho de leitura.

O presente estudo teve como objetivo discutir a legibilidade de textos para a Terceira Idade e propor um método comparativo para avaliar o desempenho das fontes. A discussão teórica ressaltou os elementos anatômicos da tipografia que repercutem significativamente na leitura. Os elementos podem ser organizados em duas categorias para gerar contraste visual necessário. A primeira categoria se envolve com a área de impressão incluindo as variáveis traço, altura-x e as extensões e a segunda categoria envolve a área não impressa como espaços internos e entre letras.

O Efeito Aglomerativo se relaciona com essas variáveis criando uma mancha ilegível de texto. Esse efeito se torna ainda mais frequente em pessoas com baixa acuidade visual. Nesse sentido ter parâmetros que verifiquem o desempenho tipográfico e evitem ruídos visuais é fundamental.

O método proposto mensura as variáveis tipográficas como altura-x, traço, extensões, entre letras e espaço interno para calcular o coeficiente do Efeito Aglomerativo. O resultado aponta que fontes arejadas contribuem para diminuir a aglomeração tipográfica.

Por outro lado, há outras variáveis tipográficas que melhoram o desempenho da leitura como a utilização de elementos de diferenciação tipográfica. Portanto, não há uma fonte universal, capaz de atender a todos os públicos, por isso é fundamental compreender os problemas de cada leitor para selecionar a fonte mais adequada para a leitura.

\section{Referências}

ARAÚJO, E, P. Um estudo sobre Etnografia aplicada ao Design. Rio de Janeiro: PUC-Rio, 2012. Dissertação (Mestrado em Design), Pontífica Universidade Católica do Rio de Janeiro, 2012.

ARDITI, Aries, CHO, Jianna. Serifs and font legibility. In: Vision Research. New York, 2005. p. 2926-2933

BERNARD, Michael; LIAS, Corrina; MILLS, Melissa. The effects of font type and size on the legibility and reading time of online text by older adults. In: Conference on Human Factors in Computing Systems. New York, 2001. p. 175-176.

BRINGHURST, Robert. Elementos do estilo tipográfico. São Paulo: Martins Fontes, 2007.

BURT, CYRIL; COOPER, W. F., MARTIN, J. L. A psychological study of typography. In: The British Journal of Statistical Psychology. 1955. p. 29-65.

CAMARANO, Ana Amélia; KANSO, Solange; MELLO, Juliano Leitão e. Como Vive o Idoso Brasileiro?. In: Os novos idosos brasileiros: muito além dos 60?. Rio de Janeiro: IPEA, 2004.

CHUNG, Susana T. L. The Effect of Letter Spacing on Reading Speed in Central and Peripheral Vision. In: Investigative Ophthalmology \& Visual Science. 2002, Vol. 43, No. 4, p. 1270-1276.

CLARKSON, John; COLEMAN, Roger; KEATES, Simeon; LEBBON, CHERIE. Inclusive Design: Design for the whole population. Cambridge: Springer-Verlag London, 2013.

FARIAS, Bruno Serviliano Santos; GUIMARÃES, Márcio James; MARQUES, Arthur José Silva. TIPOGRAFIA INCLUSIVA: proposta de análise de elementos tipográficos em materiais didáticos para a terceira idade. In:

Anais do 8 Congresso Internacional de Design da Informação. Blucher, 2017. 
FRUTIGER, Adrian. Sinais e símbolos. São Paulo: Martins Fontes, 2007.

GROEGER, Lena. How typography can save your life. In: Home: ProPublica < https://www.propublica.org/article /how-typography-can-save-your-life> 30/04/2017.

KITCHEL, J. Elaine. APH Guidelines for Print Document Design. In: Home: APH < http://www.aph.org/research/design-guidelines/> 14/02/2018.

LEEUW, Renske de. Special Font For Dyslexia?. 2010. Dissertação (Mestrado em Psicologia). University of Twente. Enschede.

MEÜRER, Mary Vonni; GONÇALVES, Berenice Santos; CORREIO, Vilson João Batista. 2014. Tipografia e baixa visão: uma discussão sobre a legibilidade. In: Projética. Londrina. Londrina, 2014. p. 33-46.

NINE, Paul. Typography and the aging eye: typeface legibility for older viewers with vi-sion problems. In: Home: Aiga < http://www.aiga.org/typography-and-the-aging-eye>, 30/04/2017. 2006.

PIJPKER, Tineke. Reading performance of dyslexics with a special font and a colored background. 2013. Dissertação (Mestrado em Psicologia). University of Twente. Enschede.

SOARES, João Marcelo Ribeiro. Design gráfico ergonômico: método para verificação de níveis de usabilidade de fontes tipográficas para texto em suportes impressos e digitais. 2016. Tese (Doutorado em Design) - Universidade Estadual Paulista. Faculdade de Arquitetura, Artes e Comunicação, Bauru.

SOUSA, Miguel. Guia de Tipos: Métodos para o uso das Fontes de PC. Estugarda, 2002

TSCHICHOLD, Jan. Vida nova na tipologia. O livro ideal. In: Textos clássicos do design gráfico. São Paulo: Martins Fontes, 2010, p. 46-50.

UNOSTIPOSDUROS. Cómo se crea una Tipografía Digital: O como introducirse al diseño de tipográfico mediante FontLab. In: CampusParty. Valencia, 2010.

VIEIRA, Rosane Maria da Silva. Um estudo sobre o design de livros para a terceira idade. Dissertação de Mestrado. Programa de Pós-Graduação em Design da Universidade Federal do Rio Grande do Sul. Porta Alegre. 2011. 